\title{
Lactobacillus namurensis sp. nov., isolated from a traditional Belgian sourdough
}

\author{
Correspondence \\ Ilse Scheirlinck \\ Ilse.Scheirlinck@ugent.be
}

\author{
Ilse Scheirlinck, ${ }^{1,2}$ Roel Van der Meulen, ${ }^{3}$ Ann Van Schoor, ${ }^{1,2}$ \\ Ilse Cleenwerck, ${ }^{2}$ Geert Huys, ${ }^{1}$ Peter Vandamme, ${ }^{1}$ Luc De Vuyst ${ }^{3}$ \\ and Marc Vancanneyt ${ }^{2}$
}
${ }^{1}$ Laboratory of Microbiology, Department of Biochemistry, Physiology and Microbiology, Ghent University, K. L. Ledeganckstraat 35, B-9000 Ghent, Belgium
${ }^{2}$ BCCM/LMG Bacteria Collection, Department of Biochemistry, Physiology and Microbiology, Ghent University, K. L. Ledeganckstraat 35, B-9000 Ghent, Belgium
${ }^{3}$ Research Group of Industrial Microbiology and Food Biotechnology, Department of Applied Biological Sciences and Engineering, Vrije Universiteit Brussel, Pleinlaan 2, B-1050 Brussels, Belgium

\begin{abstract}
A biodiversity study on lactic acid bacteria (LAB) occurring in traditional Belgian sourdoughs resulted in the isolation of two Lactobacillus isolates, LMG $23583^{\top}$ and LMG 23584, that could not be assigned to any recognized LAB species. The two isolates were initially investigated by means of phenylalanyl-tRNA synthase (pheS) gene sequence analysis and were found to occupy a separate position relative to recognized Lactobacillus species present in the pheS database. Subsequently, their phylogenetic affiliation was determined by $16 \mathrm{~S}$ rRNA gene sequence analysis, indicating that the two isolates belong to the Lactobacillus buchneri species group with Lactobacillus zymae, Lactobacillus acidifarinae and Lactobacillus spicheri as closest relatives. Whole-cell protein analysis (SDS-PAGE) and amplified fragment length polymorphism fingerprinting of whole genomes confirmed their separate taxonomic status. DNA-DNA hybridization experiments, DNA G +C content, growth characteristics and biochemical features demonstrated that the two isolates represent a novel Lactobacillus species, for which the name Lactobacillus namurensis sp. nov. is proposed. The type strain is LMG $23583^{\top}$ (=CCUG $52843^{\top}$ ).
\end{abstract}

Fermented foods produced from cereals, for example beer, spirits, sake, porridge and baked goods, have a long history of nutritional and economic importance. One of the ancient means of cereal fermentation is the traditional sourdough process (Vogel et al., 1999). Sourdough is a mixture of flour and water that is fermented with lactic acid bacteria (LAB) and yeasts (Gänzle et al., 1998; Vogel et al., 1999). LAB predominate the microbial community in this complex ecosystem and are responsible for the acidification (mainly lactic acid) of the raw material and the production of acetic acid, ethanol, aroma compounds, bacteriocins, exopolysaccharides and several enzymes (Leroy \& De Vuyst, 2004). Because of the broad metabolic potential of LAB, interest in them as starter cultures for the maintenance of food safety and quality as well as for the production of novel products

Abbreviations: AFLP, amplified fragment length polymorphism; LAB, lactic acid bacteria.

The GenBank/EMBL/DDBJ accession numbers for the 16S rRNA gene sequences of Lactobacillus namurensis LMG $23583^{\top}$ and LMG 23584 are AM259119 and AM259120, respectively.

A cluster analysis of protein profiles of the novel strains and related type strains is available as supplementary material in IJSEM Online. with improved nutritional properties is increasing. Owing to the large variety of cereals and fermentation conditions used, sourdoughs have been shown to harbour a large diversity of LAB species. In recent years, several novel Lactobacillus species isolated from sourdough have been described, including Lactobacillus pontis (Vogel et al., 1994), L. panis (Wiese et al., 1996), L. paralimentarius (Cai et al., 1999), L. frumenti (Müller et al., 2000), L. mindensis (Ehrmann et al., 2003), L. spicheri (Meroth et al., 2004), L. rossiae (Corsetti et al., 2005), L. hammesii (Valcheva et al., 2005), L. zymae (Vancanneyt et al., 2005), L. acidifarinae (Vancanneyt et al., 2005) and L. nantensis (Valcheva et al., 2006).

During a study on the biodiversity of LAB in traditional Belgian sourdoughs, two Lactobacillus isolates could not be clearly placed within any recognized species of the genus by means of genotypic and phenotypic methods. In the present study, the taxonomic position of these two isolates in the genus Lactobacillus was determined.

The sourdough used in this study originated from a spontaneous fermentation of a mixture of wheat, rye and 
spelt flour. The sourdough was maintained by backslopping and was sampled during two investigations in August 2004 and November 2005 from a bakery in the province of Namur, Belgium. Samples were taken aseptically, stored at $4{ }^{\circ} \mathrm{C}$ and analysed within $24 \mathrm{~h}$. Sourdough samples were suspended $(1: 10, \mathrm{w} / \mathrm{v})$ and serially diluted in peptone-physiological solution $[0.1 \%(\mathrm{w} / \mathrm{v})$ bacteriological peptone (L37; Oxoid) and $0.85 \%(\mathrm{w} / \mathrm{v}) \mathrm{NaCl}$. Isolates LMG $23583^{\mathrm{T}}$ and LMG 23584 were incubated at $30^{\circ} \mathrm{C}$ under aerobic conditions on MRS5 agar, containing $0.1 \mathrm{~g}$

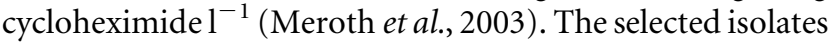
were checked for bacteriological purity by successive plating on MRS5 agar (without cycloheximide) and stored in Microbank tubes (Pro-Lab Diagnostics) at $-80^{\circ} \mathrm{C}$. Isolates LMG $23583^{\mathrm{T}}$ and LMG 23584 respectively originated from the August 2004 and November 2005 sampling investigations. Gram-staining, cell morphology, catalase activity and all further experiments were performed by using cultures grown for $24 \mathrm{~h}$ on MRS5 medium at $30^{\circ} \mathrm{C}$ under aerobic conditions, unless otherwise indicated. In the two sets of sourdough isolates obtained during the sampling investigations of August 2004 and November 2005, six (15\% of total) and three (30\% of total) isolates, respectively, were found to belong to the new taxon represented by isolates LMG $23583^{\mathrm{T}}$ and LMG 23584. Other LAB species retrieved from the two sourdough samples included L. paralimentarius, L. hammesii, Lactobacillus brevis and Lactobacillus plantarum.

The taxonomic position of the sourdough LAB isolates LMG $23583^{\mathrm{T}}$ and LMG 23584 was initially investigated using phenylalanyl-tRNA synthase (pheS) gene sequence analysis (Naser et al., 2005). Analysis of pheS gene sequences has proved to be an excellent tool for identification of Lactobacillus isolates and delineation of novel taxa (S. M. Naser, P. S. R. Dawyndt, B. Hoste, D. Gevers, K. Vandemeulebroecke, I. Cleenwerck, M. Vancanneyt and J. Swings, unpublished; Vancanneyt et al., 2006). Genomic DNA was extracted as described by Gevers et al. (2001). The primers for pheS sequencing were PheS-21-F and PheS-23$\mathrm{R}$, with amplification conditions and sequencing reactions as described by Naser et al. (2005). Sequences were imported into BioNumerics version 4.0 software (Applied Maths), aligned and compared by using the neighbour-joining method with available sequences of nearly all recognized Lactobacillus species. The two new sourdough isolates clustered together with a sequence similarity of $100 \%$ and constituted a distinct branch in the Lactobacillus buchneri species group, showing sequence similarities below $85 \%$ with the other members of the group (Fig. 1). Interspecies gaps within the genus based on pheS gene sequences normally exceed $7 \%$ (S. M. Naser, P. S. R. Dawyndt, B. Hoste, D. Gevers, K. Vandemeulebroecke, I. Cleenwerck, M. Vancanneyt and J. Swings, unpublished), which suggested that the two isolates represent a novel Lactobacillus species.

The phylogenetic position of strains LMG $23583^{\mathrm{T}}$ and LMG 23584 was further studied by $16 \mathrm{~S}$ rRNA gene sequence analysis. Genomic DNA was extracted as described above.

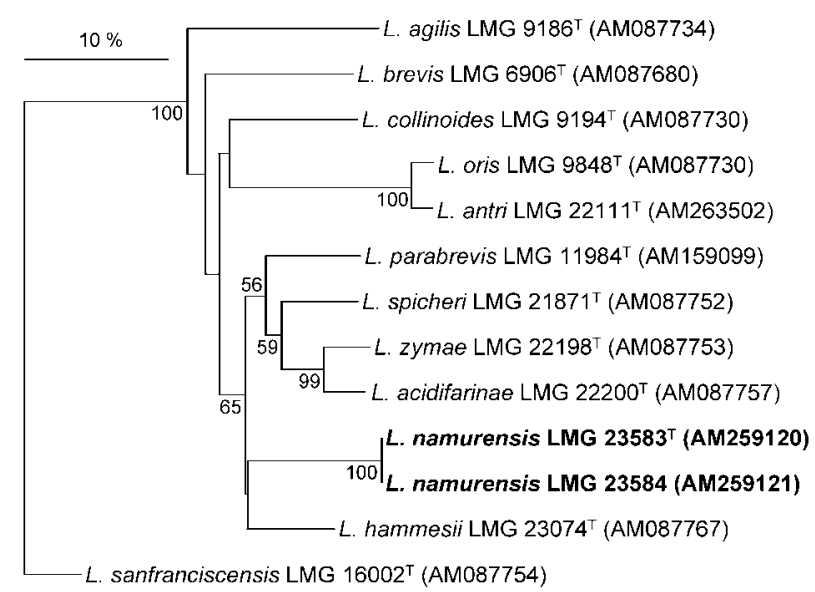

Fig. 1. Neighbour-joining tree based on pheS gene sequence data showing the relationships between the sourdough isolates LMG $23583^{\top}$ and LMG 23584 and related reference strains. Lactobacillus sanfranciscensis LMG $16002^{\top}$ was used as the outgroup. Bootstrap percentages (based on 500 replications) $\geqslant 50 \%$ are indicated at branch points. Bar, $10 \%$ sequence divergence.

$16 \mathrm{~S}$ rRNA gene amplification, purification and sequencing were performed as described by Vancanneyt et al. (2006). The sequences obtained (continuous stretches of $1518 \mathrm{bp}$ ) were deposited in and aligned and clustered with sequences from the EMBL database. A phylogenetic tree was constructed with the neighbour-joining method by using the BioNumerics version 4.0 software package. Unknown bases were discarded for analysis. The statistical reliability of the tree was evaluated by bootstrap analysis of 500 replicates and the tree topology was also confirmed using maximum-parsimony and maximum-likelihood cluster analysis. The 16S rRNA gene sequences of strains LMG $23583^{\mathrm{T}}$ and LMG 23584 were $100 \%$ similar, and their phylogenetic position within the L. buchneri group was confirmed. Nearest neighbours to the two new strains were L. spicheri LMG $21871^{\mathrm{T}}$, L. zymae LMG $22198^{\mathrm{T}}$ and $L$. acidifarinae LMG $22200^{\mathrm{T}}$, with $16 \mathrm{~S}$ rRNA gene sequence similarities of $98.2,98.7$ and $98.7 \%$, respectively (Fig. 2).

The sourdough LAB isolates were also investigated using SDS-PAGE of cellular proteins. Extraction and gel electrophoresis were performed according to the method described by Pot et al. (1994) for Gram-positive bacteria. Densitometric digitization of patterns was performed by using an LKB 2202 Ultrascan Laser Densitometer (LKB). Normalization of densitometric traces was performed with GelCompar version 4.2 software (Applied Maths). Numerical analysis with profiles available in an extensive in-house database was performed by using the Pearson product moment correlation coefficient and the unweighted pair-group method using arithmetic averages (UPGMA) with BioNumerics version 4.0. Between the two isolates, minor differences were observed in the intensity of 


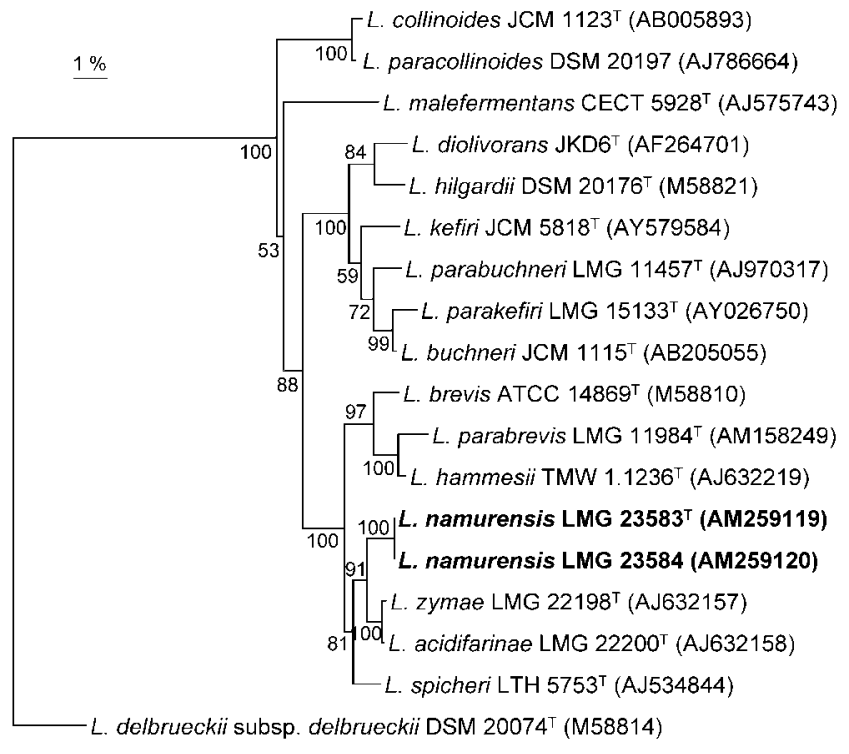

Fig. 2. Phylogenetic tree derived from 16S rRNA gene sequence analysis showing the phylogenetic position of strains LMG $23583^{\top}$ and LMG 23584 among related taxa. The tree was generated by the neighbour-joining method, and Lactobacillus delbrueckii subsp. delbrueckii DSM 20074 ${ }^{\top}$ was used as the outgroup. Bootstrap percentages (based on 500 replications) $\geqslant 50 \%$ are indicated at branch points. Bar, $1 \%$ sequence divergence.

dominant bands situated in a molecular mass range of 30-40 kDa. Comparison of the protein profiles, omitting the latter zone, resulted in a distinct branch for isolates LMG $23583^{\mathrm{T}}$ and LMG 23584 (see Supplementary Fig. S1 available in IJSEM Online).

To confirm the unique genotypic position of strains LMG $23583^{\mathrm{T}}$ and LMG 23584 in the L. buchneri group and to verify strain-specific differences, amplified fragment length polymorphism (AFLP) fingerprinting of whole genomes was performed. Extraction and purification of total genomic DNA were done as described above. AFLP analysis was performed according to the protocol of Thompson et al. (2001) with several modifications. Total DNA was digested with EcoRI and TaqI restriction enzymes. Fragments were amplified using the primers E01 (5'-GACTGCGTACCAATTCA-3'), T01 (5'-CGATGAGTCCTGACCGAA-3'), E03 (5'-GACTGCGTACCAATTCG-3') and T03 (5'CGATGAGTCCTGACCGAG-3'). The resulting electrophoretic profiles were normalized using GeneScan 3.1 software (Applera), and tables of peaks, containing fragments of 50-536 bp, were transferred into BioNumerics version 4.0. AFLP patterns were compared with profiles of LAB reference taxa using the Dice coefficient and UPGMA linkage. Cluster analysis of AFLP band patterns generated with primer pair E01/T01 (Fig. 3) confirmed the unique taxonomic position of strains LMG $23583^{\mathrm{T}}$ and LMG 23584 and also indicated that they were genotypically closely related. Using three different primer pairs (E01/T01, E01/ T03 and E03/T03), minor but reproducible band position variations in the AFLP patterns of the two isolates could be observed with the E01/T01 primer pair, suggesting that strains LMG $23583^{\mathrm{T}}$ and LMG 23584 were genotypically slightly different (Fig. 3).

The $\mathrm{G}+\mathrm{C}$ contents of the DNA of strains LMG $23583^{\mathrm{T}}$ and LMG 23584 were determined. DNA was enzymically degraded into nucleosides as described by Mesbah et al. (1989). The nucleoside mixture was separated by HPLC using a Waters SymmetryShield C8 column maintained at $37^{\circ} \mathrm{C}$. The solvent was $0.02 \mathrm{M}\left(\mathrm{NH}_{4}\right) \mathrm{H}_{2} \mathrm{PO}_{4}(\mathrm{pH} 4.0)$ with $1.5 \%$ acetonitrile. Non-methylated $\lambda$ phage DNA (Sigma) was used as the calibration reference. The DNA G+C content of strains LMG $23583^{\mathrm{T}}$ and LMG 23584 was $52 \mathrm{~mol} \%$, similar to the values determined for $L$. spicheri (55 mol\%), L. zymae (53-54 mol\%) and L. acidifarinae (51 mol\%) (Meroth et al., 2004; Vancanneyt et al., 2005).

DNA-DNA hybridizations were performed between strain LMG $23583^{\mathrm{T}}$ and the type strains of the three most closely related species (L. acidifarinae, $L$. spicheri and L. zymae) (Figs 1 and 2). DNA was extracted from $0.75-1.25 \mathrm{~g}$ (wet wt) cell mass using the protocol described by Gevers et al. (2001) with the following modifications. Volumes were increased tenfold for large-scale application. After the addition of $20 \%$ SDS and glass beads, cells were mixed for $30 \mathrm{~s}$. Subsequently, $16.5 \mathrm{ml} \mathrm{TE}$ buffer $(10 \mathrm{mM}$ Tris/ $\mathrm{HCl}$, $100 \mathrm{mM}$ EDTA, $\mathrm{pH} 8.0$ ) and $5 \mathrm{ml} 5 \mathrm{M} \mathrm{NaCl}$ was added, followed by $10 \mathrm{~min}$ incubation at $65^{\circ} \mathrm{C}$. Chloroform/ isoamyl alcohol extraction and ethanol and RNase treatment were performed as described by Marmur (1961). DNA-DNA hybridizations were performed with biotinlabelled probes in microplate wells (Ezaki et al., 1989), by using an HTS7000 Bio Assay Reader (Perkin Elmer) for the fluorescence measurements. The hybridization temperature was $44^{\circ} \mathrm{C}$ in the presence of $50 \%$ formamide. Reciprocal experiments were performed for every pair of strains and the standard deviation ranged from 0.1 to $9.9 \%$. Levels of DNA-DNA relatedness between strain LMG $23583^{\mathrm{T}}$ and $L$. spicheri LMG $21871^{\mathrm{T}}$, L. zymae LMG $22198^{\mathrm{T}}$ and $L$. acidifarinae LMG $22200^{\mathrm{T}}$ were 34,25 and $18 \%$, respectively.

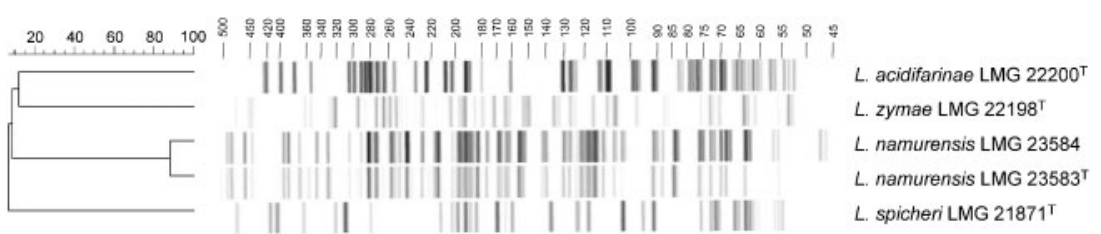

Fig. 3. Cluster analysis of digitized AFLP band patterns of strains LMG $23583^{\top}$ and LMG 23584 and their closest phylogenetic relatives. The corresponding dendrogram was constructed from the UPGMA linkage of Dice coefficients. 
These values are well below the threshold of $70 \%$ suggested for species delineation (Stackebrandt \& Goebel, 1994), indicating that strain LMG $23583^{\mathrm{T}}$ and the genotypically highly related strain LMG 23584 represent a novel species in the genus Lactobacillus.

Growth characteristics of isolates LMG $23583^{\mathrm{T}}$ and LMG 23584 were determined in MRS broth ( $\mathrm{pH}$ 5.4) (de Man et al., 1960). Growth was tested at 15 and $45^{\circ} \mathrm{C}$ and in the presence of 5, 6 and $7 \% \mathrm{NaCl}$. Aerobic and anaerobic growth and production of gas from $2 \%$ glucose and $2 \%$ gluconate in MRS broth ( $\mathrm{pH}$ 5.4, without the addition of triammonium citrate) were also investigated. Arginine hydrolysis was tested in a medium containing $0.5 \%$ tryptone, $0.5 \%$ yeast extract, $0.3 \%$ L-arginine, $0.05 \%$ glucose and $0.2 \% \mathrm{~K}_{2} \mathrm{HPO}_{4}(\mathrm{pH} 7.0$ ), with methyl orange as indicator. The isomeric type of lactate was determined enzymically (R-Biopharm). The carbohydrate fermentation patterns of the strains were determined with the API $50 \mathrm{CHL}$ system (bioMérieux) following the manufacturer's instructions with strains cultivated at $37^{\circ} \mathrm{C}$. A detailed phenotypic description is given below and characteristics that differentiate strain LMG $23583^{\mathrm{T}}$ from its closest relatives, $L$. spicheri, L. zymae and L. acidifarinae, are summarized in Table 1 .

On the basis of the data presented, strains LMG $23583^{\mathrm{T}}$ and LMG 23584 are considered to represent a novel species of the genus Lactobacillus, for which the name Lactobacillus namurensis sp. nov. is proposed.

Table 1. Phenotypic characteristics of strain LMG $23583^{\top}$ and type strains and reference strains of their closest relatives

Strains: 1, L. spicheri LMG $21871^{\mathrm{T}}$; 2, L. zymae LMG $22198^{\mathrm{T}} ; 3, \mathrm{~L}$. zymae LMG 22199; 4, L. acidifarinae LMG 22200 $;$ 5, LMG $23583^{\mathrm{T}}$ (an identical carbohydrate fermentation pattern was obtained for strain LMG 23584). +, Positive after $48 \mathrm{~h}$ incubation; $(+)$, positive after 5 days incubation; - , negative. All strains were positive after $48 \mathrm{~h}$ incubation for ribose and were negative for 2-ketogluconate.

\begin{tabular}{|lccccc|}
\hline Production of acid from: & $\mathbf{1}$ & $\mathbf{2}$ & $\mathbf{3}$ & $\mathbf{4}$ & $\mathbf{5}$ \\
\hline D-Arabitol & - & + & + & + & - \\
Galactose & + & + & - & + & + \\
Aesculin & - & - & - & - & + \\
5-Ketogluconate & + & - & - & - & - \\
Lactose & - & + & - & - & - \\
Mannitol & $(+)$ & + & - & + & $(+)$ \\
Melibiose & + & $(+)$ & - & - & $(+)$ \\
Methyl $\alpha$-D-glucoside & $(+)$ & - & - & - & - \\
D-Xylose & + & + & - & + & - \\
Methyl $\beta$-xyloside & - & - & - & - & + \\
\hline
\end{tabular}

\section{Description of Lactobacillus namurensis sp. nov.}

Lactobacillus namurensis (na.mur'en.sis. N.L. masc. adj. namurensis pertaining to the province of Namur, Belgium, from where the type strain was isolated).

Cells are Gram-positive, catalase-negative, non-motile, nonspore-forming rods. Cells occur singly or in pairs, and are $2-10 \mu \mathrm{m}$ in length and $0.5-1 \mu \mathrm{m}$ wide. After 2 days incubation on MRS5 agar, colonies are beige, circular with an irregular surface and approximately $0.5-1 \mathrm{~mm}$ in diameter. Cells grow well in liquid or solid MRS under aerobic or anaerobic conditions. Grows at $15^{\circ} \mathrm{C}$ in the presence of 5,6 and $7 \% \mathrm{NaCl}$ but not at $45^{\circ} \mathrm{C}$. Both D- and L-lactate are produced in equimolar amounts and glucose is metabolized heterofermentatively. Ammonium is produced from arginine. Gas is produced from glucose and gluconate. Produces acid from ribose, methyl $\beta$-D-xyloside, galactose, glucose, fructose, mannitol, $\mathrm{N}$-acetylglucosamine, aesculin, maltose, melibiose and gluconate, but not from glycerol, erythritol, D-arabinose, L-arabinose, D-xylose, adonitol, mannose, sorbose, rhamnose, dulcitol, inositol, sorbitol, methyl $\alpha$-D-mannoside, methyl $\alpha$-D-glucoside, amygdalin, arbutin, salicin, cellobiose, lactose, sucrose, trehalose, inulin, melezitose, raffinose, starch, glycogen, xylitol, gentiobiose, D-turanose, D-lyxose, D-tagatose, D- or Lfucose, D- or L-arabitol or 2- or 5-ketogluconate. The DNA $\mathrm{G}+\mathrm{C}$ content is $52 \mathrm{~mol} \%$.

The type strain, LMG $23583^{\mathrm{T}}\left(=\mathrm{CCUG} 52843^{\mathrm{T}}\right)$, was isolated from an artisanal sourdough manufactured with wheat, rye and spelt flour in the province of Namur, Belgium.

\section{Acknowledgements}

We are grateful for the financial support of the Flemish Institute for the Promotion of Innovation by Science and Technology in Flanders (IWT), in particular SBO project 'New Strategy for the Development of Functional and Performant Starter Cultures for Foods in Function of Food Qualitomics'. We also thank the owners and staff of the bakery in Namur for providing the sourdough samples used in this study. We further acknowledge financial support from the Research Council of the Vrije Universiteit Brussel (BOF and GOA projects). The Fund for Scientific Research-Flanders is acknowledged for financial support and for the postdoctoral fellowship of G. H.

\section{References}

Cai, Y. M., Okada, H., Mori, H., Benno, Y. \& Nakase, T. (1999). Lactobacillus paralimentarius sp. nov., isolated from sourdough. Int J Syst Bacteriol 49, 1451-1455.

Corsetti, A., Settanni, L., van Sinderen, D., Felis, G. E., Dellaglio, F. \& Gobbetti, M. (2005). Lactobacillus rossii sp. nov., isolated from wheat sourdough. Int J Syst Evol Microbiol 55, 35-40.

Ehrmann, M. A., Müller, M. R. A. \& Vogel, R. F. (2003). Molecular analysis of sourdough reveals Lactobacillus mindensis sp. nov. Int J Syst Evol Microbiol 53, 7-13. 
Ezaki, T., Hashimoto, Y. \& Yabuuchi, E. (1989). Fluorometric deoxyribonucleic acid-deoxyribonucleic acid hybridization in microdilution wells as an alternative to membrane-filter hybridization in which radioisotopes are used to determine genetic relatedness among bacterial strains. Int J Syst Bacteriol 39, 224-229.

Gänzle, M. G., Ehmann, M. \& Hammes, W. P. (1998). Modeling of growth of Lactobacillus sanfranciscensis and Candida milleri in response to process parameters of sourdough fermentation. Appl Environ Microbiol 64, 2616-2623.

Gevers, D., Huys, G. \& Swings, J. (2001). Applicability of rep-PCR fingerprinting for differentiation of Lactobacillus species. FEMS Microbiol Lett 205, 31-36.

Leroy, F. \& De Vuyst, L. (2004). Lactic acid bacteria as functional starter cultures for the food fermentation industry. Trends Food Sci Technol 15, 67-78.

de Man, J. C., Rogosa, M. \& Sharpe, E. (1960). A medium for the cultivation of lactobacilli. J Appl Bacteriol 23, 130-135.

Marmur, J. (1961). A procedure for the isolation of deoxyribonucleic acid from microorganisms. J Mol Biol 3, 208-218.

Meroth, C. B., Walter, J., Hertel, C., Brandt, M. J. \& Hammes, W. P. (2003). Monitoring the bacterial population dynamics in sourdough fermentation processes using PCR-denaturing gradient gel electrophoresis. Appl Environ Microbiol 69, 475-482.

Meroth, C. B., Hammes, W. P. \& Hertel, C. (2004). Characterisation of the microbiota of rice sourdoughs and description of Lactobacilius spicheri sp. nov. Syst Appl Microbiol 27, 151-159.

Mesbah, M., Premachandran, U. \& Whitman, W. B. (1989). Precise measurement of the $\mathrm{G}+\mathrm{C}$ content of deoxyribonucleic acid by high-performance liquid chromatography. Int J Syst Bacteriol 39, 159-167.

Müller, M. R. A., Ehrmann, M. A. \& Vogel, R. F. (2000). Lactobacillus frumenti sp. nov., a new lactic acid bacterium isolated from rye-bran fermentations with a long fermentation period. Int $J$ Syst Evol Microbiol 50, 2127-2133.

Naser, S. M., Thompson, F. L., Hoste, B., Gevers, D., Dawyndt, P., Vancanneyt, M. \& Swings, J. (2005). Application of multilocus sequence analysis (MLSA) for rapid identification of Enterococcus species based on rpoA and pheS genes. Microbiology 151, 2141-2150.
Pot, B., Vandamme, P. \& Kersters, K. (1994). Analysis of electrophoretic whole-organism protein fingerprints. In Chemical Methods in Prokaryotic Systematics, pp. 493-521. Edited by M. Goodfellow \& A. G. O’Donnell. Chichester: Wiley.

Stackebrandt, E. \& Goebel, B. M. (1994). A place for DNA-DNA reassociation and $16 \mathrm{~S}$ ribosomal RNA sequence analysis in the present species definition in bacteriology. Int J Syst Bacteriol 44, 846-849.

Thompson, F. L., Hoste, B., Vandemeulebroecke, K. \& Swings, J. (2001). Genomic diversity amongst Vibrio isolates from different sources determined by fluorescent amplified fragment length polymorphism. Syst Appl Microbiol 24, 520-538.

Valcheva, R., Korakli, M., Onno, B., Prevost, H., Ivanova, I., Ehrmann, M. A., Dousset, X., Gänzle, M. G. \& Vogel, R. F. (2005). Lactobacillus hammesii sp. nov., isolated from French sourdough. Int J Syst Evol Microbiol 55, 763-767.

Valcheva, R., Ferchichi, M., Korakli, M., Ivanova, I., Gänzle, M. G., Vogel, R. F., Prévost, H., Onno, B. \& Dousset, X. (2006). Lactobacillus nantensis sp. nov., isolated from French wheat sourdough. Int J Syst Evol Microbiol 56, 587-591.

Vancanneyt, M., Neysens, P., De Wachter, M., Engelbeen, K., Snauwaert, C., Cleenwerck, I., Van der Meulen, R., Hoste, B., Tsakalidou, E. \& other authors (2005). Lactobacillus acidifarinae sp. nov. and Lactobacillus zymae sp. nov., from wheat sourdoughs. Int J Syst Evol Microbiol 55, 615-620.

Vancanneyt, M., Naser, S. M., Engelbeen, K., De Wachter, M., Van der Meulen, R., Cleenwerck, I., Hoste, B., De Vuyst, L. \& Swings, J. (2006). Reclassification of Lactobacillus brevis strains LMG 11494 and LMG 11984 as Lactobacillus parabrevis sp. nov. Int J Syst Evol Microbiol 56, 1553-1557.

Vogel, R. F., Bocker, G., Stolz, P., Ehrmann, M., Fanta, D., Ludwig, W., Pot, B., Kersters, K., Schleifer, K. H. \& Hammes, W. P. (1994). Identification of lactobacilli from sourdough and description of Lactobacillus pontis sp. nov. Int J Syst Bacteriol 44, 223-229.

Vogel, R. F., Knorr, R., Müller, M. R. A., Steudel, U., Gänzle, M. G. \& Ehrmann, M. A. (1999). Non-dairy lactic fermentations: the cereal world. Antonie van Leeuwenhoek 76, 403-411.

Wiese, B. G., Strohmar, W., Rainey, F. A. \& Diekmann, H. (1996). Lactobacillus panis sp. nov., from sourdough with a long fermentation period. Int J Syst Bacteriol 46, 449-453. 